\title{
A City Divided: "Fragmented" Urban and Literary Space in 20th-Century Buenos Aires
}

MARIANELA D'APRILE

University of California, Berkeley

When analyzing the state of Latin American cities, particularly large ones like Buenos Aires, São Paolo and Rio de Janeiro, scholars of urbanism and sociology often lean heavily on the term "fragmentation." Through the 1980s and 1990s, the term was quickly and widely adopted to describe the widespread state of abutment between seemingly disparate urban conditions that purportedly prevented Latin American cities from developing into cohesive wholes and instead produced cities in pieces, fragments. This term, "fragmentation," along with the idea of a city composed of mismatching parts, was central to the conception of Buenos Aires by its citizens and immortalized by the fiction of Esteban Echeverría, Julio Cortázar and César Aira. The idea that Buenos Aires is composed of discrete parts has been used throughout its history to either proactively enable or retroactively justify planning decisions by governments on both ends of the political spectrum. The 1950 s and 60 s saw a series of governments whose priorities lay in controlling the many newcomers to the city via large housing projects. Aided by the perception of the city as fragmented, they were able to build monster-scale developments in the parts of the city that were seen as "apart." Later, as neoliberal democracy replaced socialist and populist leadership, commercial centers in the center of the city were built as shrines to an idealized Parisian downtown, separate from the rest of the city. The observations by scholars of the city that Buenos Aires is composed of multiple discrete parts, whether they be physical, economic or social, is accurate. However, the issue here lies not in the accuracy of the assessment but in the word chosen to describe it. The word fragmentation implies that there was a "whole" at once point, a complete entity that could be then broken into pieces, fragments. Its current usage also implies that this is a natural process, out of the hands of both planners and inhabitants. Leaning on the work of Adrián Gorelik, Pedro Pírez and Marie-France Prévôt-Schapira, and utilizing popular fiction to supplement an understanding of the urban experience, I argue that fragmentation, more than a naturally occurring phenomenon, is a fabricated concept that has been used throughout the twentieth century and through today to make all kinds of urban planning projects possible.

\section{"FRAGMENTATION" AS AN URBAN CONCEPT}

When analyzing the state of Latin American cities, particularly large ones like Buenos Aires, Sao Paolo and Rio de Janeiro, scholars of urbanism and sociology often lean heavily on the term "fragmentation." Through the 1980s and 1990s, the term was quickly and widely adopted to describe the widespread state of abutment between seemingly disparate urban conditions that purportedly prevented Latin American cities from developing into cohesive wholes and instead produced cities in pieces - fragments. ${ }^{1}$ This term, "fragmentation," along with the idea of a city composed of mismatching parts was central to the conception of Buenos Aires by its citizens long before it was adopted by scholars in the 20th century. The conception of Buenos Aires as being made up of discrete parts has been used throughout its history to either enable or justify planning decisions. The 1950s and 60s saw a series of governments whose priorities lay in controlling the many newcomers to the city via large housing projects. Aided by the perception of the city as fragmented, they were able to build monster-scale developments in the parts of the city that were seen as "apart." Later, as neoliberal democracy replaced socialist leadership, commercial centers in the center of the city were built as shrines to an idealized Parisian downtown, separate from the rest of the city. The term's negative connotation implies that fragmentation is something that needs to be fixed, a notion that has enabled planning entities to make decisions under the guise of public benefit. I will argue that fragmentation, more than a naturally occurring phenomenon, is a fabricated concept that has been used throughout the twentieth century and through today to make urban planning projects possible.

Beyond the beginnings of a quasi-universal grid, the Buenos Aires of the nineteenth century was largely a blank canvas. To prevent it from 
growing uncontrollably, a protective ring around the city was demarcated in 1888 , when the development of the city was confined to a concentrated area near the port and along a central avenue. This decision makes clearly evident the priorities of planners of the time: protect what had developed of the city so far, preciously valued for its European charm, from the threat of the uncontrolled, chaotic, as yet untouched "wild." A map from 1892, showing the city center developed along Avenida Nueve de Julio and Avenida de Mayo (Figure 1), depicts the city as it would come to be perceived by its users and by its developers: as two distinct pieces. One, densely constructed, strongly gridded, belonged to the Parisian, idealized city. The other, vast, open, would be blamed for the city's social and economic problems, and eventually become the testing ground for potential solutions to these issues in the twentieth century.

\section{IMAGINING AN IDEAL}

The importance of the worded depiction of the city spans as far back as 1538 , when a group of explorers led by Pedro de Mendoza landed on the shores of the Río de la Plata. Ulrich Schmidl, a German member of the crew, wrote that they found "a place inhabited by Indian folk, numbering about three thousand people" and that on the shores of this river they founded a town they called "Nuestra Señora del Buen Ayre," or "Our Lady of Good Wind."2 Five years later the Spaniards, exhausted by the constant attacks by the "Indian folk," burned down the city and sailed back across the Atlantic, leaving little physical trace of their presence. What did remain, however, were Schmidl's sixteenth-century travelogues, immortalizing the short life of the then-nascent Buenos Aires in his written descriptions. Schmidl's texts are documentary, not literary, but nevertheless mark the founding of Buenos Aires as a city of narration, clearly defined by words on a page and less so by its easily-burned walls. Buenos Aires was founded again, this time in a more permanent fashion, in 1580 by Juan de Garay. But this founding was based less on the convenience of the port's location than it was on the prior existence of Buenos Aires, as Rosalba Campra suggests in La selva en el damero. ${ }^{3}$ Thanks to the writings of Schmidl, Garay and his crew had an imagined sense that they were already some place - that the city existed before their arrival, that it was there, waiting, its soil ready for founding. So even before its population began pushing beyond its three-foot walls, Buenos Aires existed in mythological form, transcending its physicality.

The idealized image of the city captured during the late nineteenth century reflected Buenos Aires's physical development at that point in time, when little other than the gridded downtown existed within the 1888 protective ring. Adrián Gorelik credits the gridded arrangement of Buenos Aires, set in place in the 1880 s, with installing in the minds of the city's inhabitants the notion that the city was capable of extending indefinitely into space. ${ }^{4}$ The grid set up to somehow infill this future city lent the impression of the city growing homogeneously into infinity. It hinted at a possible future city that would be only complete once the grid was filled. Buenos Aires never filled the 1888 confines set up to protect it against the very quality of uncontrolled dispersion that it exhibits today, so the idea that there were two cities - a "real" Buenos Aires and one that had to catch up to it - quickly developed and was captured vividly in literature. And because the idea was propagated by literature, it was readily used by government planning agencies to justify many projects - from public housing to the conversion to historic spaces to shopping districts - throughout the twentieth century.

Literary depictions of the city clearly capture the development of Buenos Aires as a city comprised of two distinct pieces - one controlled and gridded and the other untamed, waiting to be infilled. Authors, particularly poets, of the late nineteenth century strongly communicated feelings of fear, incertitude and trepidation over the nascent quality of the city, and nervously perceived the untamed country surrounding the city that was declared the Federal Capital in 1880. The city's growth boomed in 1870 no doubt due to the building of a formal port and to the expansion of both the national and local railway systems. ${ }^{5}$ The transition was not an easy one, however, as the short story "The Slaughteryard" by Esteban Echeverría suggests. "The Slaughteryard," the first short story in the history of Argentine literature, paints an image of a city threatened by its natural borders. ${ }^{6}$

It happened then, in that time, a very copious rain. A huge avenue was precipitated suddenly by the Estuary of Barracas. The Plata River, growing brazenly, pushed those waters that came looking for their bed and made them run, swollen, atop fields, valleys, orchards, hamlets. The city surrounded from north to west by a waist of water and mud, and to the south by a deep, whitened ocean, cast from its towers and ravines astonished looks toward the horizon as if imploring the protection of the Highest.

In Echeverría's version of the city, just as it was beginning to grow out of its infancy and into a romanticized port city, personification gives life to an urban Buenos Aires that seems static, dominated by the greater natural forces surrounding it.

\section{FILLING THE GRID, DIVIDING THE CITY}

The twentieth century saw Buenos Aires fill its 1888 borders, reaching densely into every corner of that ubiquitous grid. But, Buenos Aires did not develop as a cohesive whole - disparate types of buildings were used to fill the parts of the grid that had lain empty since 1892. Some of the economic and social enclaves that Prévôt-Schapira credits for creating an overall fragmented city did indeed surge from the devolution and impoverishment of the working middle class, but a large part of these were built deliberately as islands within the city, particularly in the mid-twentieth century, when immigration into the city from Europe as well as from the interior of the country peaked. During this time, the State prioritized thebuilding of housing projects that would simply serve as places to put the large numbers of people over which it struggled to exert control, producing neighborhoods of informal homes next to high-end houses and country clubs. Unsurprisingly, this pattern of development led to a physically and socially uneven urban fabric.

The 1950s and 1960s were characterized by a series of public housing plans that sought to give back the "right to housing," a phrase overused by Perón and later co-opted by the military government that was to overthrow him, to the many immigrants who continued to flow into the city from European countries left weakened by war and to the 
growing number of families moving to Buenos Aires from the interior of the country. ${ }^{7}$ This was done by way of a government mandate entitled Primer Plan de Vivienda of 1952, which established three distinct types of dwellings: monoblocks, communal housing projects loosely based on the European hof, supermanzanas, large blocks of communal housing that broke the city grid, and chalets argentinos, small individual housing units. ${ }^{8}$ Amidst a floundering economy and a growing social unrest, governments found it increasingly difficult to sustain the building the nineteenth-century European grandeur of the past. But, the housing policies popular in early-twentieth-century Europe and the architectural typologies they created were relatively easy to recreate. The monoblock and the supermanzanas saw themselves built and rebuilt again even through the 1970s, as this time period was characterized by a strong political push to eradicate any and all emergency housing blocks and informal settlements. ${ }^{9}$

In 1955, a military coup known as the Revolución Libertadora overthrew Perón and, with him, the housing programs he established. The Revolución Libertadora established the Comisión Nacional de la Vivienda (CNV) a task force charged with creating a "rational geographic distribution" within the city by targeting existing problems with housing. Villas miserias posed a "threat" so great to the outward image of the city that the CNV ordered the first-ever census of these settlements and subsequently put in place the first of many plans to eradicate and replace them with more permanent housing. The plan put forth by the CNV, called the Plan de Acción Inmediata (Plan of Immediate Action) concentrated its building efforts on the south-central sector of Buenos Aires, a trend which was to be continued by the subsequent planning organizations in the 1960s and 1970s. South-central Buenos Aires, composed of the neighborhoods of Flores, Saavedra and Villa Lugano, was targeted by government housing agencies because it was, until then, largely undeveloped and an area frequently settled by newcomers to the city. ${ }^{10}$ Figure 2 shows five of the most prominent, both in scale and form, housing developments of the mid-to-late twentieth century. Although not comprehensive or exhaustive, these five developments exemplify the nature of planning during this time period - blocks placed at odd intersections and empty lots throughout the city, usually adjacent to the highway, purposely denying of the existing city grid, always abnormal and alien in their form. The fact that they are such singular forms, seemingly dropped on an already-existing fabric, reflects the way this part of the city was conceived - largely a blank canvas, open to experimentation because it did not belong to the part of the city that was so preciously appreciated and protected.

If Echeverría wrote about the threat of the wild in the city, Julio Cortázar, a century later, focused on the already-finished city and its collage-like urbanity. In his 1956 collection of short stories Final del juego, Cortázar ties the general malaise and unhappiness of his characters to their physical settings. ${ }^{11}$ In one particular short story, "Después del almuerzo," Cortázar juxtaposes the names of prominent city buildings (the Casa Rosada, or house of government, the Colón Theatre) with images of mundane everyday life. But this juxtaposition is not to give these establishments a semblance of accessibility. Rather, it is to point out the loss of the grandeur they once had.
From the other corner of the square you could barely see the bank; I took a brief moment to cross to the Casa Rosada where the soldiers always stand guard, and through the side I took off toward the Colón Passage, that street where mom says kids shouldn't go alone.

... I don't remember very well what happened in that time that I walked the Colón Passage, which is an avenue like any other. For a minute I was sitting in the low gallery of an import and export house, and then my stomach started to hurt, not like when you have to go to the bathroom right away, it was further up, in the true stomach, as if it was twisting little by little, and I wanted to breathe and it was difficult, then I had to stay still and wait for the cramp to pass, and in front of me I could see something like a green stain and little dots dancing, and dad's face, in the end it was only dad's face because I had closed my eyes, I think, and in the middle of the green stain was dad's face.

Here, the most important buildings of the city become mere backdrops to a character's physical discomfort. This Buenos Aires of the midtwentieth century is already a lost cause, not ideal by any means, but its inhabitants consider their city to be Paris, or at some point have been Paris, or to have the potential to become Paris, if only someone could do something right.

As government priorities changed, the idea that Buenos Aires wasn't "whole" and that it needed to get back to a past glory was once again used, but for different types of projects. As the nation moved out of a series of military dictatorships and established a "permanent democracy" in 1983, a major shift in planning priorities occurs. Instead of the prioritization of the "completion" of the city by building housing in its less- developed areas, the focus becomes the renovation of existing buildings within the oldest areas of the city.

It was during this time that, according to Prévôt-Schapira, Argentina ceased to be a "politically divided but socially integrated society" and instead became a society divided in both aspects. Although PrévôtSchapira's analysis has economics and sociology at its center, she concludes by stating that these inequalities have an urban result, and that it is the fabric of the city that ultimately keeps the fragments from being melded into a whole. According to Pedro Pírez, the private development of gated neighborhoods and commercial centers during the 1990s jeopardized public space in Buenos Aires and divided the city according to socio-economic status. ${ }^{12}$

In the neo-liberal economic climate of the 1990s, the focus shifted from emulating the social architecture of Europe to producing veneers of the First World through re-appropriation of abandoned spaces and historic buildings. Most prominently, the Abasto Shopping Mall, which was built in the hollowed-out shell of the Buenos Aires Central Market, and the Puerto Madero neighborhood, which was developed along the old industrial port. These architectures were made in favor of an ideal image, perpetuated by travel agencies and tourists who lauded Buenos Aires for being "the most European" of South American cities. The neo-liberalism of the late 80 s and 90s exerted a different kind of control over the city, one that fed on the nostalgia of these images to 


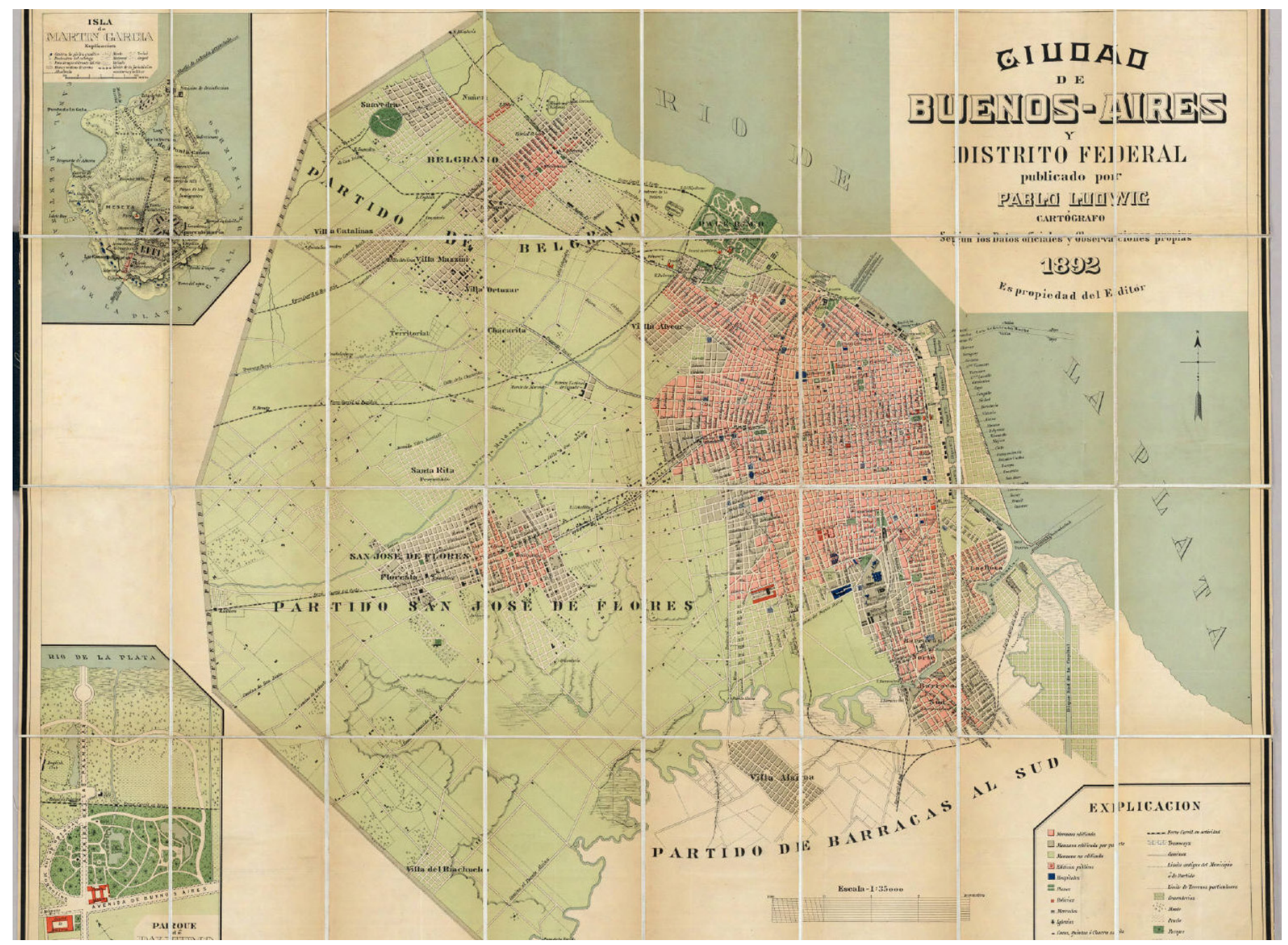

Figure 1: 1892 map of Buenos Aires by Pablo Ludwig showing the confines of the city and its development within these. Although the grid is fully fleshedout, the city remains in its infancy. (CDavid Rumsey Map Collection.

create a consumerism encouraged by the city itself. Cultural attractions in the city built during this time capitalized on the assumed value of the historic pieces of the city and rendered them easily digestible and ready for consumption.

The most prominent public space renovation project of the 1990s was that of the port area through which most of the immigrants had arrived to the city in the nineteenth century. Overtaken by industry throughout the twentieth century, this area was considered shabby and uninhabitable and abutted one of the most dangerous zones of the city. With the privatization of many public services throughout the 1990s, Argentina's economy began to position itself competitively on a global field. ${ }^{13}$ This new growth, coupled with the aspirations to return to an assumed past glory after the fall of the military dictatorship in 1983, created a need to project an outward image of prosperity and success. ${ }^{14}$ The renovation of the old port provided the idealistic vehicle for this imaged transformation. The renovation was made possible thanks in large part to private developers who bought pieces of the large swath of property. Over the course of ten years, the industrial port became the city's most expensive district, teeming with nightclubs and high-end restaurants. The renovation is considered a success and point of pride by the public - a step toward joining the ranks of the United States, all while building on soil thought of as distinctively Argentinian, the entryway for the immigrants that built the so-admired pseudo-European culture. ${ }^{15}$

The renovation of the old central market, completed as the Puerto Madero project was underway, was of a much smaller scale but had just as much media impact. The Abasto Shopping, termed as such in borrowed English, was renovated in 1999, near the end of the presidency of Carlos Menem and as the country approached an economic crisis. In a state of disrepair, the central market building was essentially gutted and turned into a shell which was then infilled with a modern, mall-like spaces. These spaces, characterized by Fernando Reati as "veneers" and by Jorge Liernur as "simulacra of the First World," have had little to no role in the cultural production and literary representations of the city. ${ }^{16}$ In fact, the image of the city conveyed by many works of the 1990s and 2000 s is that of the "city outside the city" - the places of exclusion, of social difference and poverty created by the proliferation of "public" spaces created for use only by those who can economically access them. As these spaces, located mostly in the northeastern zone of the city, have received increased attention from the city government, the spaces in the south-central section of the city have deteriorated in contrast. 


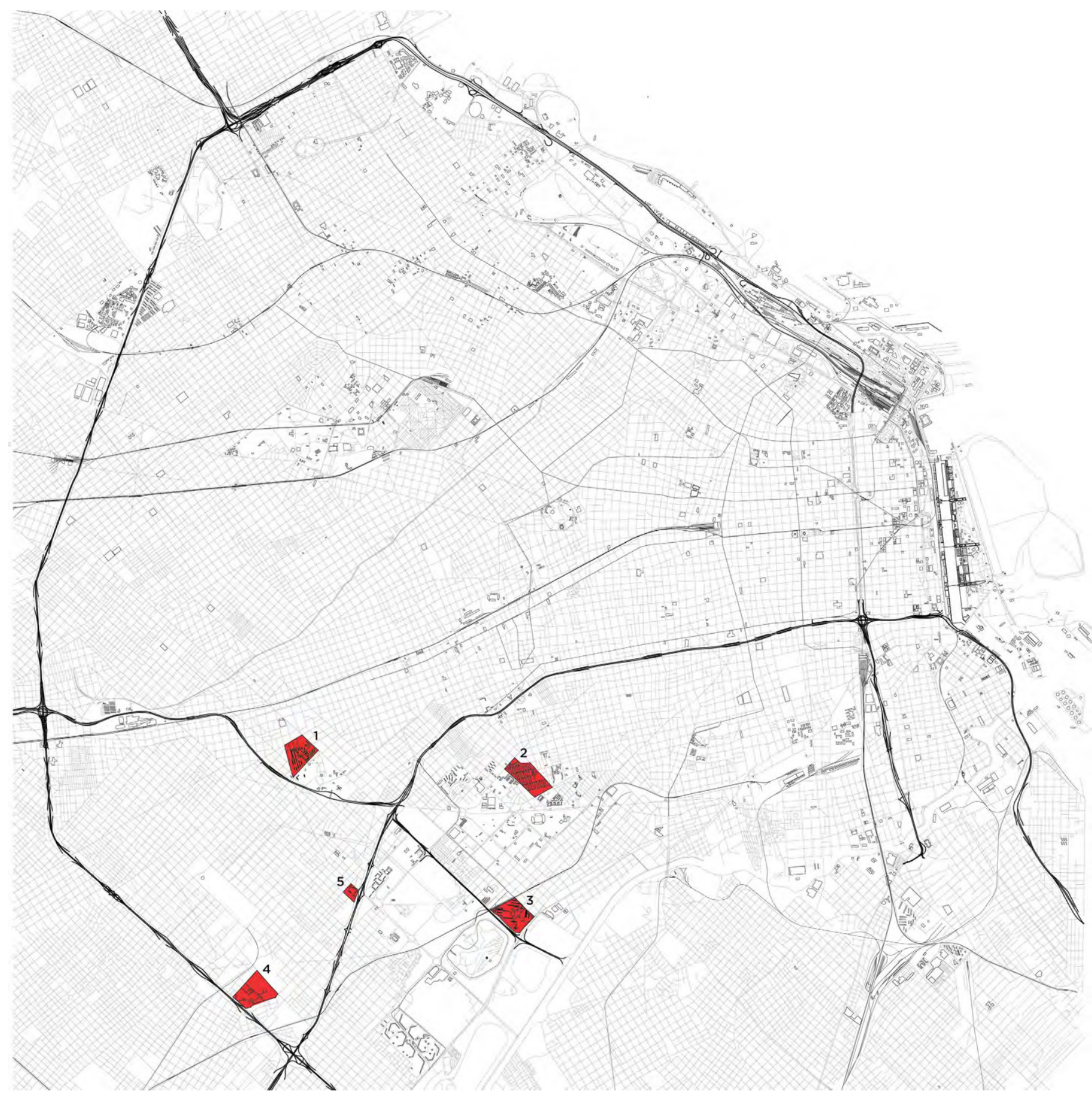

Figure 2

1. Barrio Alvear, 1954, Primer Plan de Vivienda

2. Barrio Rivadavia, 1958, Plan de Acción Inmediata

3. Barrio Soldati, 1979, Plan Alborada

4. Barrio Piedrabuena, 1981, Plan Alborada

5. Barrio Justo Suárez, 1974, Plan Municipal de Vivienda
Depictions of the city often center on spaces where public life is carried out and performed. In the late nineteenth century, this space is the street, which fittingly reflects the priorities of urban planning at the time. As the street became increasingly unsafe, the venues for public life became the neighborhood and the home. In the twentieth century, when the state undertook urban social housing projects of a massive scale, the home and the neighborhood became the focal point of literature dealing with or set in the city. Buenos Aires itself had now become an entity separate from public life, a place to where one had to travel, even when one resided inside it. Authors of the late twentieth and early 
twenty-first centuries have a particular affinity for this condition. Writers like César Aira and Roberto Fogwill create images of Buenos Aires with its least desirable areas at the center. Today's present Buenos Aires does not offer a clear venue for public life. Literature makes that clear, and so does the privatization of public spaces in the 1990s and early 2000s.

In his 1998 novel Vivir Afuera, Rodolfo Fogwill highlights the aspects of the city which marginalize its inhabitants, ultimately implying that large parts of the population do not live in the city at all, despite their physical location inside the geographical confines of the city. ${ }^{17}$ In his 2001 novel La Villa, César Aira describes Barrio Rivadavia and the street adjacent to it, Avenida Bonorino, as entities separate from the rest of the city and uses them as a setting for a murder. ${ }^{18}$

The street called Bonorino, from its beginning on Avenida Rivadavia, was labeled "Avenida" Esteban Bonorino on the signs, and no one knew why, because it was a narrow street like all the other ones. Everyone thought it was just another one of those frequent bureaucratic errors, a mix-up by clueless government workers who had ordered the signs without ever setting foot in the neighborhood. But it happened to be true, although so secretly that no one could find out. Eighteen blocks down, passing a bunch of monoblocks and warehouses and sheds and empty lots, where it seemed that the street had already ended, and where not even the most persistent walker reached, the street called Bonorino widened, transforming into the avenue it promised to be from the beginning. But it wasn't the beginning; it was the end.

The divorcing of these places from the idea of the city at large serves to preserve the ideals with which Buenos Aires has always been associated. Buenos Aires is European, modern, advanced. The ad-hoc spaces described by these authors are not, so therefore they must not be a part of the city. Buenos Aires today is still a city divided, and the large urban investments of the twentieth century have only exacerbated this condition.

\section{CONCLUSIONS}

When Gorelik, Pírez and Prévôt-Schapira refer to the condition of "fragmentation", they often reference a political and socio-economic fragmentation that happened long before the city physically manifested it. Buenos Aires has developed at the hands of politics, becoming a physical manifestation of the priorities of the governments that had a hand in shaping it. Despite differing political agendas, governments since the middle of the twentieth century have all used the idea that Buenos Aires is composed of two parts to develop it. The observations by scholars of the city that Buenos Aires is composed of multiple discrete parts, whether they be physical, economic or social, is accurate. However, the issue here lies not in the accuracy of the assessment but in the word chosen to describe it. The word fragmentation implies that there was a "whole" at once point, a complete entity that could be then broken into pieces, fragments. Its current usage also implies that this is a natural process, out of the hands of both planners and inhabitants.
The word "fragmentation" and the concept it stands for created a tangible problem whose solution city planners claimed to seek. But the proposed solutions all exacerbated the very condition they supposedly aimed to remedy, deliberately dividing the city. The housing projects in South-Central Buenos Aires, purported solutions to the city's fragmented state, only further divided its socioeconomic fabric. The historic renovations in the center of the city, although diametrically opposite in purpose, did the very same thing. The "problem" of fragmentation facilitated actions that purposely exacerbated this condition, creating spaces of exclusion and division. Viewing Buenos Aires as "fragmented" characterizes its condition as something organic and unavoidable, when in fact the spaces that make up its fabric are deliberately disparate. Buenos Aires's urban fabric has been purposely divided - if we begin to call it such, we can get closer to architectural moves that will address the reality of the city, not the idea of it.

\section{ENDNOTES}

1. Marie France Prévôt-Schapira. "Fragmentación espacial y social: conceptos y realidades." Perfiles Latinoamericanos 19. (December 2001): 38.

2. Luis L. Dominguez, ed. Conquest of the River Plate (1535-1555). Surrey: Ashgate Publishing Ltd, 2010. 7.

3. Campra, Rosalba. "Buenos Aires infundada." La selva en el damero. Espacio literario y espacio urbano en América Latina, 103-117. Pisa: Giardini Editori, 1989.

4. Adrián Gorelik. "Buenos Aires en la encrucijada: modernización y política urbana.” Miradas sobre Buenos Aires, 175-255. Buenos Aires: Siglo XXI, 2004

5. James R. Scobie. Buenos Aires: Plaza to Suburb. New York: Oxford University Press, 1974. 94.

6. Echeverría, Esteban. "El Matadero." Buenos Aires: Colihue, 1978.

7. Arnoldo Gaite, comp. Desarrollo urbano y vivienda: introducción al estudio de la acción del estado. Buenos Aires: nobuko, 2005. 27.

8. Renée Dunowicz. 90 Años de Vivienda Social en la Ciudad de Buenos Aires. Buenos Aires: Gaglianone, 2000.

9. Ibid

10. Gaite, 20.

11. Julio Cortázar. Final del juego. Buenos Aires: Alfaguara, 2006.

12. Pedro Pírez. "Expansión territorial, privatización y fragmentación en la configuración metropolitana de Buenos Aires." Cadernos Métropole 13. (2005): 11-46.

13. Ryan Centner. "Microcitizenships: Fractious Forms of Urban Belonging after Argentine Neoliberalism." International Journal of Urban and Regional Research vol. 36, no. 32. 2011. 336-362.

14. Jorge Francisco Liernur. "Buenos Aires fin de siglo: el desconcierto de la forma." Punto de Vista 59. (December 1997): 13-19.

15. Beatriz Cuenya and Manuela Corral. "Empresarialismo, economía del suelo y grandes proyectos urbanos: el modelo de Puerto Madero en Buenos Aires." EURE, Volume 37, Number 111. (May 2011): 25-45.

16. Fernando Reati. "La ciudad futura." Postales del porvenir, la literatura de anticipación en la Argentina neoliberal (1985-1999), 87-136. Buenos Aires: Editorial Biblos, 2006.

17. Rodolfo Fogwill. Vivir Afuera. Buenos Aires: Editorial Sudamericana, 1998.

18. César Aira. La Villa. Buenos Aires: emecé, 2001. 